\title{
PENGARUH HIPERTENSI TERHADAP AMBANG PENDENGARAN
}

\author{
Moonika Todingan \\ Palandeng OI \\ Pelealu OCP \\ Bagian / SMF Telinga Hidung Tenggorok-Bedah Kepala Leher \\ Fakultas Kedokteran, Universitas Sam Ratulangi \\ BLU RSU Prof. Dr. R. D. Kandou Manado \\ Email: todingan.moonika@gmail.com
}

\begin{abstract}
Background: Hypertension is an important health problem because it has a high prevalence and can cause organ damage. One of hypertension target organ damage is the auditory system that can cause an increase in the threshold of hearing (hearing loss). Hypertension effect on hearing loss can affect a person's quality of life.
\end{abstract}

Objective: Determine the effect of hypertension on the threshold of hearing.

Methods: 80 samples consisted of 40 samples hypertension group and 40 samples comparison group (normotensive group), men and women, aged 36-65 years. Hypertension was measured with a blood pressure measurement using a mercury sphygmomanometer. Hearing was measured with auditory threshold measurement using a pure tone audiometry at frequencies between 250 to $8000 \mathrm{~Hz}$. This research was analytic study with cross-sectional research design. Chi-square test was used to see the effect of hypertension on the threshold of hearing.

Result: There are 24 people with hypertension who have hearing loss, 16 people with hypertension do not have a hearing loss, 6 normotensive people with hearing loss, and 34 normotensive people do not have a hearing loss. This relationship is getting significant results $(\mathrm{p}<0,05)$ is $\mathrm{p}<0,001$.

Conclusion: Hypertension is a risk factor for hearing loss.

Keyword: hypertension, hearing loss

Latar Belakang: Hipertensi merupakan masalah kesehatan yang penting karena mempunyai prevalensi yang cukup tinggi dan dapat menimbulkan kerusakan organ target. Salah satu kerusakan organ target hipertensi adalah sistem pendengaran yang menyebabkan peningkatan ambang pendengaran (gangguan pendengaran). Hipertensi berpengaruh terhadap gangguan pendengaran yang dapat mempengaruhi kualitas hidup seseorang.

Tujuan: Menentukan pengaruh hipertensi terhadap ambang pendengaran.

Metode: 80 sampel terdiri dari 40 sampel kelompok hipertensi dan 40 sampel kelompok pembanding (kelompok normotensi), laki-laki dan perempuan, umur 36-65 tahun. Hipertensi diukur dengan pengukuran tekanan darah menggunakan alat tensimeter air raksa. Pendengaran diukur dengan pengukuran ambang pendengaran menggunakan alat audiometri nada murni pada frekuensi antara 250 sampai $8000 \mathrm{~Hz}$. Penelitian ini merupakan jenis penelitian analitik dengan desain penelitian cross sectional. Digunakan uji Chi-Square untuk melihat adanya pengaruh hipertensi terhadap ambang pendengaran.

Hasil: Terdapat 24 orang hipertensi yang mengalami gangguan pendengaran, 16 orang hipertensi tidak mengalami gangguan pendengaran, 6 orang normotensi mengalami gangguan pendengaran, dan 34 orang normotensi tidak mengalami gangguan pendengaran. Hubungan ini mendapatkan hasil yang signifikan $\mathrm{p}<0,05$ yaitu $\mathrm{p}<0,001$.

Kesimpulan: Hipertensi merupakan salah satu faktor resiko gangguan pendengaran.

Kata kunci: hipertensi, gangguan pendengaran. 
Hipertensi atau tekanan darah tinggi, kadang disebut hipertensi arterial adalah suatu kondisi kronik yang ditandai dengan peningkatan tekanan darah arteri. Diperlukan keadaan kerja jantung yang lebih keras dari normal agar sirkulasi dalam pembuluh darah dapat dipertahankan. ${ }^{1}$

Hipertensi merupakan masalah kesehatan yang penting karena prevalensinya yang tinggi. Hipertensi menyebabkan 7,5 juta kematian atau $1,8 \%$ dari seluruh total kematian di dunia. Pada tahun 2008 prevalensi hipertensi pada umur lebih dari 25 tahun mencapai 40\%. ${ }^{2}$ Di Amerika 67 juta orang dewasa yaitu sebesar $31 \%$ atau 1 dari 3 orang mengalami hipertensi. Menurut Centers for Disease Control and Prevention (CDC), hipertensi merupakan faktor resiko mayor penyakit ginjal. ${ }^{3}$ Menurut penelitian, prevalensi hipertensi di Indonesia berdasarkan pengukuran dan riwayat penyakit adalah 32,2\% dengan prevalensi tertinggi ditemukan di Provinsi Kalimantan Selatan (39,6\%) dan prevalensi terendah ditemukan di Papua Barat $(20,1 \%){ }^{4}$

\section{METODE}

Penelitian dilakukan di Bagian Interna dan Bagian THT-KL BLU RSU Prof. Dr. R. D. Kandou pada bulan November sampai Desember 2013. Penelitian ini merupakan jenis penelitian analitik dengan desain penelitian cross sectional. Populasi target adalah semua orang yang menderita hipertensi dan populasi terjangkau adalah semua pasien poli hipertensi BLU RSU Prof. Dr. R. D. Kandou Manado. Sampel pada penelitian ini sebanyak 80 orang, yang terdiri dari 40 orang kelompok hipertensi dan 40 orang kelompok pembanding (kelompok normotensi). Kriteria inklusi pada penelitian ini; usia 36-65 tahun, menderita hipertensi $\geq 1$ tahun untuk kelompok hipertensi di poli hipertensi, dan normotensi untuk kelompok pembanding di poli THT-KL.
Terdapat penelitian yang menghubungkan antara hipertensi dengan gangguan pendengaran. Penelitian yang dilakukan di Brazil membahas tentang kerusakan organ telinga dalam pada pasien yang menderita hipertensi, didapatkan bahwa pasien dengan tekanan darah sistolik $\geq 140 \mathrm{mmHg}$ dan tekanan darah diastolik $\geq 90 \quad \mathrm{mmgHg}$ memiliki kemungkinan lebih besar untuk mengalami peningkatan ambang pendengaran (gangguan pendengaran). ${ }^{5}$

Menurut World Health Organization (WHO), sekitar $5 \%$ populasi di dunia, yaitu 360 juta orang mengalami gangguan pendengaran; 328 juta diantaranya adalah penderita dewasa dan sisanya (32 juta) adalah anak-anak. ${ }^{6}$

Gangguan pendengaran dapat mempengaruhi aspek sosial dan emosional individu. Keterbatasan berkomunikasi dapat memberikan pengaruh yang signifikan terhadap kehidupan, yaitu rasa kesepian, terisolasi, dan frustasi, terutama bagi orang yang sudah lama mengalami gangguan pendengaran. ${ }^{6}$

\section{HASIL}

Jumlah sampel yang diperoleh sebanyak 80 orang, yaitu 40 orang pada kelompok hipertensi dan 40 orang pada kelompok normotensi.

\section{Karakteristik Sampel}

Tabel 1. Distribusi frekuensi karakteristik sampel

\begin{tabular}{ccc}
\hline Karakteristik & f (orang) & Persentase \\
\hline Jenis & & \\
Kelamin & & \\
Laki-laki & 25 & $31.3 \%$ \\
Perempuan & 55 & $68.7 \%$ \\
\hline Total & $\mathbf{8 0}$ & $\mathbf{1 0 0 \%}$ \\
\hline Umur & & \\
36-45 tahun & 12 & $15 \%$ \\
46-55 tahun & 21 & $26.2 \%$ \\
56-65 tahun & 47 & $58.8 \%$ \\
\hline Total & $\mathbf{8 0}$ & $\mathbf{1 0 0 \%}$ \\
\hline
\end{tabular}


Pada tabel di atas, terlihat bahwa mayoritas sampel berjenis kelamin perempuan, yaitu sebanyak 55 orang (68.7\%).

Karakteristik umur sampel yang didapat melalui informed consent berkisar 36-65 tahun. Pada tabel di atas terlihat bahwa mayoritas sampel berada pada kategori umur 56-65 tahun sebanyak 47 orang (58.8\%).

Tabel 2. Distribusi frekuensi pasien hipertensi

\begin{tabular}{ccc}
\hline Karakteristik & f (orang) & Persentase \\
\hline Hipertensi & & \\
Ya & 40 & $50 \%$ \\
Tidak & 40 & $50 \%$ \\
\hline Total & $\mathbf{8 0}$ & $\mathbf{1 0 0 \%}$ \\
\hline
\end{tabular}

Berdasarkan hasil distribusi frekuensi pada tabel di atas terlihat bahwa pasien hipertensi sebanyak 40 orang (50\%) dan pasien yang tidak hipertensi sebanyak 40 orang (50\%).

Tabel 3. Distribusi pasien hipertensi dengan peningkatan ambang pendengaran berdasarkan kategori lama hipertensi

\begin{tabular}{lccc}
\hline \multirow{2}{*}{$\begin{array}{c}\text { Lama } \\
\text { Hipertensi }\end{array}$} & \multicolumn{2}{c}{ Gangguan } & \\
\cline { 2 - 3 } & \multicolumn{2}{c}{ Pendengaran } & TOTAL \\
\cline { 2 - 3 } 1-5 tahun & 9 & Tidak & \\
6-9 tahun & 5 & 4 & 15 \\
$>9$ tahun & 10 & 6 & 16 \\
TOTAL & 24 & 16 & 40 \\
\hline
\end{tabular}

Tabel 3 di atas hasilnya menunjukkan bahwa pasien hipertensi dengan gangguan pendengaran terbanyak berada pada kategori lama hipertensi $>9$ tahun dengan jumlah 10 orang.

Tabel 4. Distribusi sampel pasien hipertensi berdasarkan kategori derajat hilangnya pendengaran

\begin{tabular}{cccc}
\hline $\begin{array}{c}\text { Derajat } \\
\text { Ambang } \\
\text { Dengar }\end{array}$ & HGP & HTGP & TOTAL \\
\hline Normal & 0 & 16 & 16 \\
Ringan & 21 & 0 & 21 \\
Sedang & 3 & 0 & 3 \\
TOTAL & 24 & 16 & 40 \\
\hline
\end{tabular}

Keterangan :

$\mathrm{HGP}=$ Hipertensi dengan gangguan pendengaran.

HTGP = Hipertensi dan tidak disertai dengan gangguan pendengaran.

Tabel 4 di atas hasilnya menunjukkan bahwa pasien hipertensi dengan gangguan pendengaran terbanyak berada pada derajat gangguan pendengaran ringan dengan jumlah 21 orang.

\section{Analisis Data}

Tabel 5. Pengaruh hipertensi terhadap ambang pendengaran.

\begin{tabular}{cccc}
\hline \multirow{2}{*}{ HIPERTENSI } & \multicolumn{2}{c}{ Ambang Dengar } & \\
\cline { 2 - 3 } & Normal & $\begin{array}{c}\text { Tidak } \\
\text { Normal }\end{array}$ & \\
\cline { 2 - 3 } Ya & 16 & 24 & 40 \\
Tidak & 34 & 6 & 40 \\
TOTAL & 50 & 30 & 80 \\
\hline
\end{tabular}

Berdasarkan hasil uji normalitas didapatkan bahwa data seluruh variabel penelitian tidak terdistribusi normal dimana masing-masing variabel memiliki nilai signifikansi $<0,05$. Oleh karena itu untuk uji hipotesis secara statistik digunakan metode pengujian NonParametrik uji Chi-Square (SPSS 20.0 for Windows). Pengujian menggunakan 2 sisi data dengan tingkat signifikansi $<0,05$, didapatkan $\mathrm{P}$ value (Asymo. Sig. 2-sided < 0,05 yaitu $\mathrm{P}<0,001$ yang berarti hipotesis null (Ho) ditolak dengan kesimpulan terdapat perbedaan signifikan status gangguan pendengaran dari pasien hipertensi. Perbedaan ini menunjukkan 
terdapat pengaruh hipertensi terhadap gangguan pendengaran.

Tabel 6. Pengaruh umur pasien hipertensi terhadap ambang pendengaran

\begin{tabular}{lccccc}
\hline $\begin{array}{l}\text { UMUR } \\
\text { (tahun) }\end{array}$ & HGP & HTGP & THGP & THTGP & TOTAL \\
\hline $36-45$ & 0 & 1 & 0 & 11 & 12 \\
$46-55$ & 3 & 5 & 2 & 11 & 21 \\
$56-65$ & 21 & 10 & 4 & 12 & 47 \\
\hline TOTAL & 24 & 16 & 6 & 34 & 80 \\
\hline
\end{tabular}

Keterangan :

HGP = Hipertensi dengan gangguan pendengaran.

HTGP = Hipertensi dan tidak disertai dengan gangguan pendengaran.

THGP = Tidak hipertensi tetapi memiliki gangguan pendengaran.

THTGP = Tidak hipertensi dan tidak mengalami gangguan pendengarah.

Berdasarkan hasil uji normalitas didapatkan bahwa data seluruh variabel penelitian tidak terdistribusi normal dimana masing-masing variabel memiliki nilai signifikansi $<0,05$. Oleh karena itu untuk uji hipotesis secara statistik digunakan metode pengujian NonParametrik uji Chi-Square (SPSS 20.0 for Windows). Pengujian menggunakan 2 sisi data dengan tingkat signifikansi $<0,05$, didapatkan $\mathrm{P}$ value (Asymo. Sig. 2-sided < 0,05 yaitu $\mathrm{P}=0,002$ yang berarti terdapat perbedaan signifikan status gangguan pendengaran dari umur pasien hipertensi. Perbedaan ini menunjukkan terdapat pengaruh umur pasien hipertensi terhadap gangguan pendengaran.

\section{BAHASAN}

Penelitian ini menunjukkan adanya hubungan antara hipertensi dan gangguan pendengaran pada individu antara umur 36-65 tahun. Hal ini sesuai dengan penelitian Maria yang menyebutkan bahwa ada hubungan antara hipertensi dan gangguan pendengaran. Penelitian yang dilakukan di Brazil tersebut membahas tentang kerusakan organ telinga dalam pada pasien yang menderita hipertensi, didapatkan bahwa pasien dengan tekanan darah sistolik $\geq 140 \mathrm{mmHg}$ dan tekanan darah diastoli $\mathbf{9 0} \mathrm{mmHg}$ memiliki kemungkinan lebih besar untuk mengalami peningkatan ambang pendengaran. ${ }^{5}$

Karakteristik sampel pada penelitian ini ditinjau berdasarkan umur, jenis kelamin, lama hipertensi, dan derajat gangguan pendengaran. Penelitian ini dapat dipengaruhi oleh faktor-faktor lain, seperti penyakit-penyakit tertentu, obatobat ototoksik, dan faktor kebisingan yang dapat menyebabkan bias penelitian, karena itu untuk mengurangi bias penelitian, terdapat kriteria eksklusi untuk pasien yang mengalami diabetes, penyakit telinga yang dapat mengganggu pendengaran, obat-obat ototoksik, dan faktor bising.

Pada penelitian ini screening hipertensi diperoleh melalui pengukuran tekanan darah masing-masing sampel, sedangkan untuk screening sampel dengan gangguan pendengaran diperoleh melalui pemeriksaan audiometri.

Sebagian besar pasien hipertensi yang mengalami gangguan pendengaran, terbanyak pada pasien yang mengalami hipertensi selama lebih dari 9 tahun (Tabel 3). Hingga saat ini belum terdapat penelitian yang membuktikan bahwa lama hipertensi berpengaruh terhadap gangguan pendengaran. Hasil penelitian ini juga belum dapat menjelaskan hubungan antara lama hipertensi dengan gangguan pendengaran karena responden yang diperoleh di poli sebagian besar mengalami lama hipertensi lebih dari 9 tahun.

Pasien hipertensi terbanyak berada pada derajat gangguan pendengaran ringan (Tabel 4). Hal ini berbeda dengan penelitian yang dilakukan dengan 552 sampel pasien hipertensi, berusia antara 14 hingga 84 tahun, dan hasilnya 43,6\% 
berada pada kategori hilang pendengaran moderat. Begitu juga dengan penelitian yang dilakukan oleh Maria yang menggunakan 392 sampel, dan hasilnya menunjukkan sampel terbanyak berada pada kategori hilang pendengaran moderat dengan $56,6 \%{ }^{5}$

Hasil penelitian dari tabel 5 secara statistik diperoleh bahwa hipertensi berpengaruh terhadap gangguan pendengaran dengan signifikansi $\mathrm{P}<0,001$. Dalam hal ini dapat dilihat bahwa hipertensi berpengaruh terhadap gangguan pendengaran. Hal ini sesuai dengan penelitian de Moraes et al di Brazil yang memperlihatkan hubungan jelas antara hipertensi dan gangguan pendengaran yang mempunyai nilai signifikansi $<0,05$, yaitu $\mathrm{P}=0,0034{ }^{7}$

Lippincott dan Rarey meneliti hubungan antara tingkat $\mathrm{Na}$, K-ATPase isoform yang terdapat di dinding lateral koklea pada tikus hipertensi dan tikus normotensi. Secara fisiologis, Na,KATPase terdistribusi normal pada jaringan koklea dan berperan penting dalam mikrohomeostasis koklea dengan mengatur jumlah $\mathrm{Na}+$ dan $\mathrm{K}+$ pada cairan endolimfa dan perilimfa. Penelitian ini menunjukkan bukti bahwa Na, K-ATPase berada dalam tingkat yang signifikan pada stria vaskularis dan daerah suprastria dari tikus hipertensi yang menyebabkan perubahan dalam homeostasis koklea dengan efek pada penurunan pendengaran. ${ }^{8}$

Hasil penelitian dari tabel 6 secara statistik diperoleh bahwa terdapat pengaruh umur pasien hipertensi terhadap gangguan pendengaran dengan signifikansi $\mathrm{P}=0,002$. Dari hasil ini kita dapat melihat bahwa semakin tinggi usia seseorang dapat menjadi faktor resiko independen untuk gangguan pendengaran.

Beberapa penelitian juga menunjukkan bahwa hipertensi merupakan faktor yang mempercepat degenerasi organ pendengaran yang berkaitan dengan penuaan. ${ }^{9,10}$
Penelitian lain menjelaskan bahwa gangguan pendengaran yang terjadi dengan penuaan berhubungan dengan insufisiensi mikrosirkulatori yang terjadi akibat oklusi pembuluh darah yang disebabkan oleh emboli, perdarahan atau vasospasme, dan ini terjadi karena sindrom hiperviskositas atau mikroangiopati yang disebabkan oleh diabetes atau hipertensi dan melalui mekanisme histopatologi yang dapat menyebabkan gangguan pendengaran sensorineural. ${ }^{7}$

Hipertensi merupakan penyakit metabolik yang berhubungan dengan komplikasi klinik, kecacatan, dan kematian. Lebih dari setengah kematian pasien yang berumur 50 ke atas berhubungan dengan penyakit kardiovaskular dan 80\% diantaranya hipertensi. Beberapa penyakit yang sering dan dapat menjadi komplikasi hipertensi yaitu stroke, penyakit hati, gangguan ginjal dan pembuluh darah perifer. ${ }^{9}$

Dalam penelitian kali ini juga telah dibuktikan bahwa hipertensi berhubungan dengan gangguan pendengaran, karena itu perlu tim multidisiplin untuk menangani kasus hipertensi ini, seperti kardiologis, nefrologis, otorinolaringologis, audiologis, dan tenaga kesehatan profesional lainnya. Perawatan terhadap hipertensi dan gangguan pendengaran akan bermanfaat untuk meningkatkan kualitas hidup seseorang yang menderita hipertensi dengan gangguan pendengaran. ${ }^{9}$

\section{SIMPULAN}

Lama hipertensi terbanyak pada pasien hipertensi yang mengalami gangguan pendengaran adalah $>9$ tahun. Pasien gangguan pendengaran terbanyak berada pada derajat gangguan pendengaran ringan.

Hipertensi berpengaruh terhadap peningkatan ambang pendengaran (gangguan pendengaran). Terdapat pengaruh umur pasien hipertensi terhadap gangguan pendengaran. 
SARAN

Perlu dilakukan penelitian lebih lanjut mengenai pengaruh lama hipertensi terhadap gangguan pendengaran dan juga perlu dilakukan penelitian lebih lanjut mengenai pengaruh hipertensi terhadap derajat gangguan pendengaran.

\section{DAFTAR PUSTAKA}

1. Nasution SR. Managemen hipertensi. In: Siregar P, Dharmeizar, Nainggolan G, Marbun MBH, Hustrini NM, Umami V, editors. Naskah Lengkap The 13 Jakarta Nephrology and Hypertension Course and Symposium on Hypertension; 2013; Jakarta, Indonesia. Jakarta: PERNEFRI (Perhimpunan Nefrologi Indonesia); 2013.

2. World Health Organization. Raised blood praisure. 2013 [cited 2013 Oct 8]. Available from: http://www.who.int/gho/ncd/risk_f actors/blood_pressure_prevalence_ text/en.

3. Centers for Disease Control and Prevention. High Blood Pressure. 2013 Mar 20 [cited 2013 Oct 8]. Available from: http://www.cdc.gov/bloodpressure/ facts.htm.
4. Rahajeng E, Tuminah S. Prevalensi hipertensi dan determinannya di Indonesia. Maj Kedokt Indon. 2009;59:582,583.

5. Maria Fernanda, Lopes AC. Relation between arterial hypertension and hearing loss. Intl. Arch. Otorhinolaryngol. 2009;13:63-68.

6. World Health Organization.

Deafness and hearing loss. 2013

Feb [cited 2013 Sep 30]. Available from:

http://www.who.int/mediacentre/fa ctsheets/fs300/en.

7. de Moraes Marchiori LL, de Almeida Rego Filho E. Matsuo T. Hypertension as a factor associated with hearing loss. Braz J Otorhinolaryngol. 2006;72:533-40.

8. Lippincott L, Rarey KE. Status of cochlear Na,K-ATPase in the aged SHR rat and its possible role in hearing loss. Ear Arch Otorhinolaryngol. 1997;254:413416.

9. Argawal S, Mishra A, Jagade M, Kasbekar V, Nagle SK. Effects of hypertension hearing. Indian $\mathrm{J}$ Otolaryngol Head Neck Surg. 2013;65:614-618.

10. Zhang J, Zhou H, Zhang G, Xu Y. A study on early hearing impairment with essential hypertension. 2009;23:731-733. 